\title{
CINÉTICA DE DETERIORAÇÃO APRESENTADA POR FILÉS DE CARPA-CAPIM (Ctenopharyngodon idella) EMBALADOS A VÁCUO SOB DIFERENTES CONDIÇÕES DE REFRIGERAÇÃO'
}

\author{
Carlos PRENTICE ${ }^{2, *}$, Ricardo Lemos SAINZ ${ }^{3}$
}

\section{RESUMO}

A diversificação da oferta de produtos pesqueiros e, as práticas de aquicultura poderão incrementar o consumo destes produtos, desde que a exigência cada vez maior dos consumidores por alimentos de melhor qualidade, frescos e naturais, seja levada em consideração. O objetivo deste trabalho foi desenvolver um estudo tecnológico visando à obtenção de um alimento minimamente processado à base de carpa-capim (Ctenopharyngodon idella), estudando os fatores que influenciam na qualidade dos filés de carpa sob embalagem com atmosfera modificada a vácuo, armazenadas a temperatura de refrigeração. Em resumo, o processamento mínimo aplicado às amostras, aliado à embalagem a vácuo permitiu aumentar a vida-útil dos filés de carpa-capim.

Palavras-chave: carpa-capim; alimentos MPR; vácuo; embalagem, refrigeração.

\section{SUMMARY}

KINETICS OF DETERIORATION PRESENTED BY VACUUM PACKAGED GRASS CARP (Ctenopharryngodon idella) FILLETS UNDER DIFFERENT REFRIGERATION CONDITIONS. The offer of fishery products and the Aquaculture practices will can increase consume if the exigency for fresh and high quality products would be attend. The objective of this work was obtain a MPR product with grass carp (Ctenopharyngodon idella), studying the factors that was important in the quality and in the deterioration of the products with modified atmosphere packaging at vacuum, stored at refrigeration temperature. In short, the MPR practices applied in the products and the vacuum packaging, allowed to increase the storage time of the grass carp fillets.

Keywords: grass carp; MPR food; vacuum; packing; refrigeration.

\section{1 - INTRODUÇÃO}

Segundo a FAO [15], a carne de pescado é a fonte protéica de origem animal mais consumida no mundo, atingindo grandes índices de consumo nos países asiáticos e países desenvolvidos. Já o Brasil, apesar de se encontrar entre os 30 maiores pólos pesqueiros mundiais, apresenta um dos mais baixos índices de consumo de pescado, em média $6,7 \mathrm{~kg}$ per capita/ano [1, $13,34]$.

$\mathrm{O}$ acondicionamento em embalagem com atmosfera modificada a vácuo é um processo tecnológico de preservação de alimentos, que em essência consiste da exposição dos alimentos à ausência de ar, controlando o desenvolvimento de microrganismos, a ação enzimática e a oxidação, principais mecanismos de deterioração de alimentos. Aliada ao processamento mínimo esta tecnologia permite um incremento significativo na oferta de pescado, com qualidade e baixo custo, criando uma nova alternativa de renda para produtores e indústrias [37]. Mas para utilização destas tecnologias é necessário que sejam conhecidos os processos deteriorativos que ocorrem nos filés de pescado minimamente processados, durante seu armazenamento [39].

\footnotetext{
1. Recebido para publicação em 08/10/2003. Aceito para publicação em 27/12/2004 (001230).

2. Depto. de Química, Laboratório de Tecnologia de Alimentos, FURG Fundação Universidade Federal do Rio Grande, Cx. Postal 474 - CEP 96201-900 Rio Grande, RS, Brasil. E-mail: dqmprent@furg.br

3. Conjunto Agrotécnico Visconde da Graça. C.T. Alimentos / Agroindústria. UFPel-Universidade Federal de Pelotas, Cx. Postal 545. CEP 96001970 Pelotas. RS. Brasil.

* A quem a correspondência deve ser enviada.
}

O pescado em geral, é um alimento muito perecível, quando comparado com outros alimentos in natura, pois apresenta uma vida-útil relativamente curta. A embalagem em atmosferas modificadas (EAM) pode aumentar a vida-útil do pescado, preservando a sua qualidade e inibindo o crescimento bacteriano. Isto poderia ajudar ao pescado a ser transportado a mercados situados a longa distância, incrementaria seu valor comercial e reduziria as perdas econômicas [29]. Vantagens adicionais que a EAM apresenta são as fáceis práticas de transporte e manuseio, a elevada disponibilidade de suprimentos e perdas físicas menores $[10,39,40,41]$.

O pescado fresco é, o que mais sofre deterioração post mortem, do músculo nos alimentos hoje consumidos, portanto as indústrias podem ter um crescimento de mercado, se puderem manter a qualidade por mais tempo, atendendo a demanda de entressafra $[5,6,7$, $12,18,30]$.

O risco inerente no pescado é devido à grande incidência de Clostridium botulinum nos ambientes aquáticos. Este risco, porém, só aparece em caso de abusos de temperatura ou de vida-útil prolongada. Se a temperatura do armazenamento e a vida-útil ficam restritas, por exemplo, a $1-2^{\circ} \mathrm{C}$ o risco é mínimo. Tem sido proposto que os riscos associados com sistemas anaeróbios podem ser reduzidos pela inclusão de pequenas quantidades de oxigênio $[2,6,9,12,13,14,15,16]$.

A embalagem com atmosfera modificada [EAM] permite aumentar a vida útil do pescado fresco, mas somente se combinada com um armazenamento a baixas temperaturas. Estas baixas temperaturas reduzirão a atividade enzimática do produto e a possibilidade de ocorrência de reações de oxidação, além disto inibem a 
ação de microrganismos anaeróbios, tais como o Clostridium botulinum [1 1, 17]. A embalagem também protege o produto de contaminações por microrganismos suspensos no ar [19, 20]. Práticas de processamento mínimo como a exposição ao $\mathrm{CO}_{2}$ ou a imersão em $\mathrm{NaCl}$ a 5\% antes do armazenamento em EAM, aumentam a vida-útil do produto [8, 27, 39], o que torna esta associação bastante significativa em termos de conservação e vida-útil do produto [39, 44, 46].

O objetivo deste trabalho foi estudar a cinética de deterioração de filés de carpa embalados a vácuo, durante seu armazenamento sob refrigeração.

\section{2 - MATERIAL E MÉTODOS}

\section{1 - Material}

\subsection{1 - Matéria-prima}

Espécimes de carpa, da variedade capim (Ctenopharyngodon idella), provenientes de criadouros das instituições de referência, foram padronizados pelo tamanho, com comprimento de 50 a $70 \mathrm{~cm}$ e peso vivo aproximado de $2,0 \mathrm{~kg}$. Os reagentes utilizados para as determinações analíticas foram todos da qualidade P. A. As embalagens utilizadas seguiram as seguintes especificações: polipropileno e nylon de 5 camadas, especial para selado a alto vácuo, com baixa permeabilidade ao oxigênio, lisas, nas dimensões de $16 \times 20 \times 0,18 \mathrm{~cm}$.

\subsection{2 - Processamento}

\section{- Pré-tratamento}

A matéria-prima (carpa-capim) foi recebida imediatamente após a captura, lavada com água potável clorada (10ppm) e colocada em banho de gelo até o momento do processamento.

\section{- Obtenção dos filés}

O pescado foi processado dentro do laboratório da indústria, procedendo-se as operações de descabeçamento, evisceração, pelado e filetagem.

\section{- Tratamento}

Os filés de carpa foram lavados novamente, primeiro em salmoura diluída ( $5 \%$ de $\mathrm{NaCl})$, para a retirada de resíduos de sangue e impurezas, e, para reduzir a capacidade de retenção de água (CRA), depois imersos em solução de hipoclorito de sódio (5ppm) para redução da carga bacteriana residual, sofrendo finalmente nova lavagem por imersão em solução salina a 10\%. Cada lavagem foi executada através de imersão por 5 minutos.

- Embalagem em atmosfera modificada a vácuo

Os filés foram acondicionados em sacos de polietileno, com tamanho e peso pré-definidos, selados a vácuo e armazenados sob temperatura de refrigeração.

\section{- Armazenamento}

Utilizando duas temperaturas distintas de armazenamento: $2 \pm 1^{\circ} \mathrm{C}$ e $8 \pm 1^{\circ} \mathrm{C}$, estas amostras foram armazenadas junto com testemunhas, minimamente processadas também, mas não embaladas a vácuo.

A Figura 1 mostra os filés de carpa-capim minimamente processados, durante seu armazenamento em estufa refrigerada.

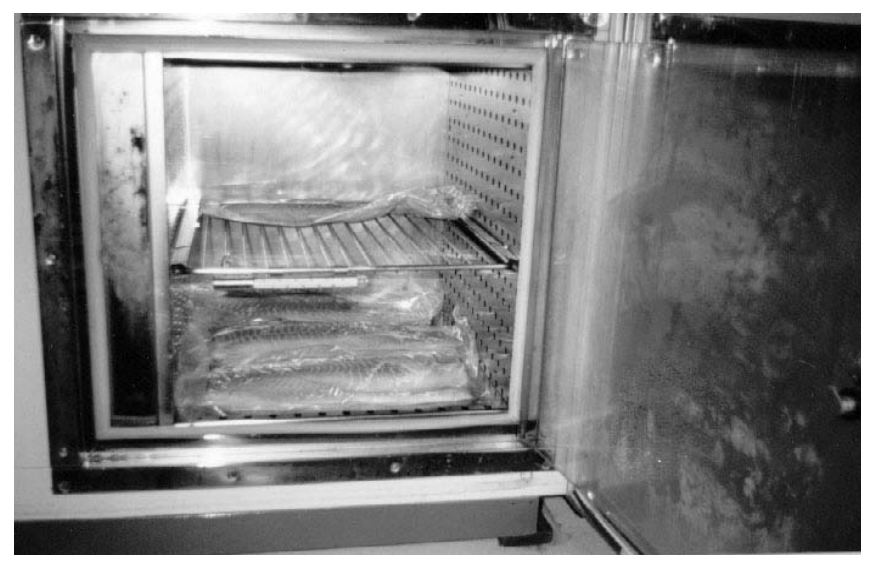

FIGURA 1. Filés de carpa embalados a vácuo, durante armazenamento em estufa.

\subsection{3 - Cinética da deterioração do produto}

Visando um melhor acompanhamento dos filés minimamente processados e, embalados a vácuo, estes foram analisados nos seguintes tempos de armazenamento: $1,7,15,30,45$ e 60 dias, determinando desta forma o comportamento dos fatores que influenciaram nesta deterioração e, principalmente, indicando se os filés chegaram a este tempo de armazenamento em condições de consumo, de acordo com as normas brasileiras. [12, 14, 25]. Foram utilizados como padrão de qualidade do produto, os índices de BVT, TBA, peróxido e o $\mathrm{pH}[3,38]$. A Figura 2 mostra o fluxograma de processamento dos filés de carpa-capim.

\section{3 - RESULTADOS E DISCUSSÃO}

\section{1 - Bases Voláteis Totais (BVT)}

A Figura 3 mostra o comportamento das BVT dos filés de carpa, embalados ou não a vácuo, durante o armazenamento.

Pode-se observar que os valores das BVT crescem com o aumento do tempo de armazenamento de forma quase constante e, que o seu comportamento é bastante semelhante, se considerarmos o uso ou não das EAM com vácuo. Isso que denota que o comportamento das reações de deterioração do pescado e, conseqüente a formação de bases voláteis segue velocidades constantes o que torna previsível seu comportamento (pelo menos até os 30 dias de armazenamento, depois há uma certa variação no crescimento dos valores das BVT, principalmente no produto armazenado com tempera- 
turas menores que $2^{\circ} \mathrm{C}$ ). Observa-se também que as BVT aumentam de forma mais lenta se o produto for armazenado a $2^{\circ} \mathrm{C}$. No caso das testemunhas sem uso de vácuo podemos observar que o aumento do índice de BVT foi muito maior, indicando que o vácuo foi efetivo na redução dos valores deste índice e, conseqüentemente na conservação dos filés. Os filés a vácuo, armazenados a $2^{\circ} \mathrm{C}$ chegaram aos 60 dias com menos de 30mg de BVT/100g [Padrão Brasileiro] e os filés a vácuo, armazenados a $8^{\circ} \mathrm{C}$ chegam aos 60 dias com valores de BVT menores que $60 \mathrm{mg}$ de BVT/100g, portanto dentro dos padrões internacionais [41]. Já os filés que não utilizaram embalagens a vácuo deterioraram mais rapidamente chegando aos 7 dias de armazenamento, já sem condições de consumo.

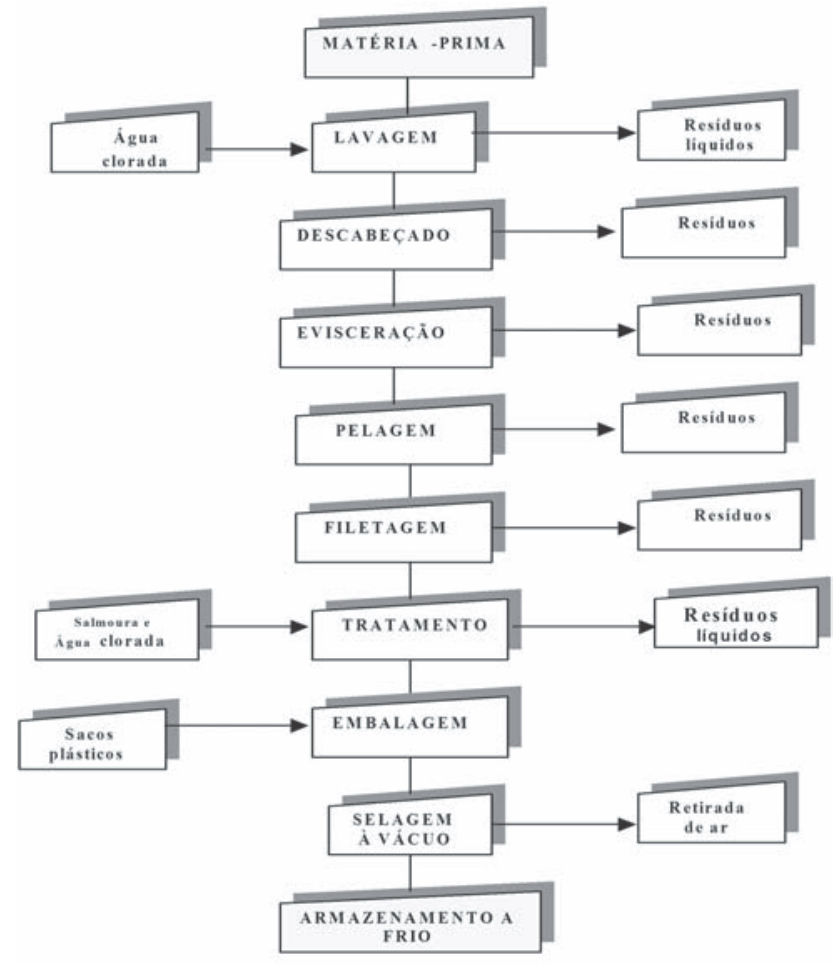

FIGURA 2. Fluxograma geral operacional utilizado para a obtenção do produto minimamente processado à base de carpa capim.

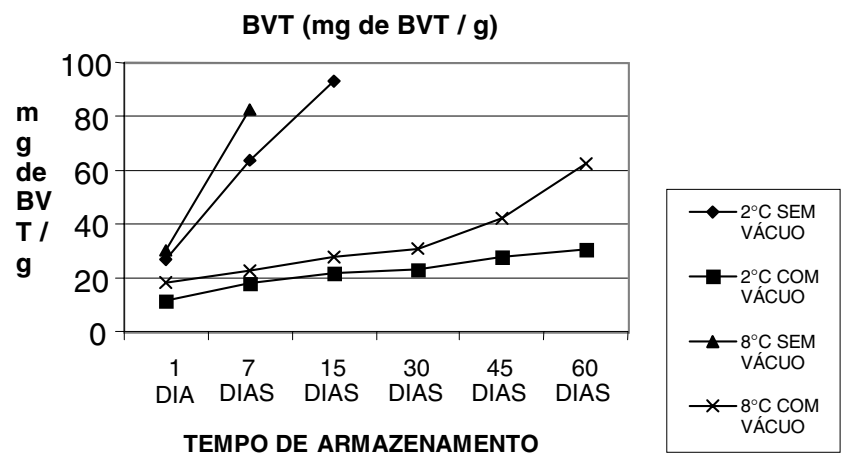

FIGURA 3. Comportamento das BVT ao longo do armazenamento dos filés de carpa.

\section{$3.2-\mathbf{p H}$}

A Figura 4 mostra a variação do $\mathrm{pH}$ dos filés de carpa minimamente processados e embalados a vácuo, durante o armazenamento.

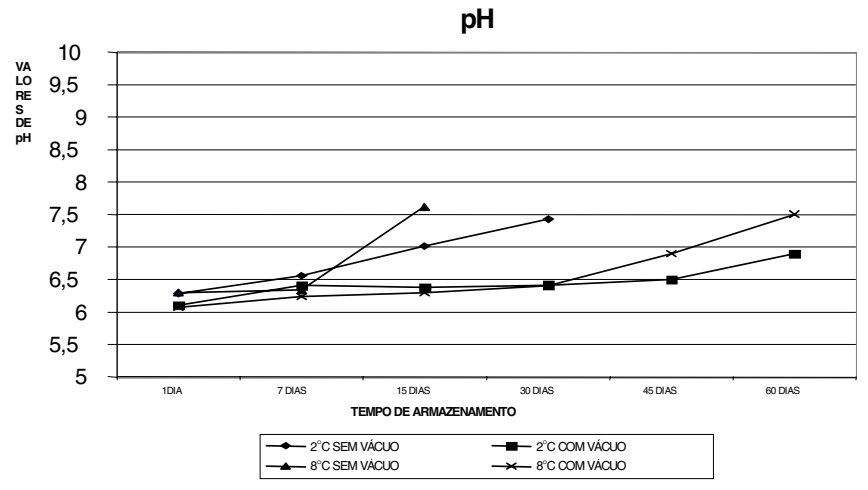

FIGURA 4. Variação do pH com relação ao tempo de armazenamento do produto.

À medida que aumenta o tempo de armazenamento observa-se aumento dos valores do $\mathrm{pH}$, devido à formação das bases voláteis, oriundas da decomposição protéica do pescado [22]. O comportamento do $\mathrm{pH}$ é bastante semelhante ao do índice das BVT, pois os valores de $\mathrm{pH}$ das testemunhas sem vácuo são maiores que os valores dos filés embalados a vácuo. A temperatura de armazenamento mais baixa apresentou valores finais de $\mathrm{pH}$, para um mesmo período de armazenamento, menores que os apresentados pelos filés armazenados a $8^{\circ} \mathrm{C}$, o que indica que a temperatura também é efetiva sobre a deterioração dos filés de carpa-capim minimamente processados [23, 27].

\section{3 - Estabilidade lipidica}

Os valores dos Índices de TBA e de Peróxidos são pouco significativos em termos da conservação deste produto, devido ao fato da carpa ser um pescado magro, mas que se apresentaria significante se o conteúdo lipídico fosse alto. Pode-se observar que o comportamento dos valores de peróxido aproximam-se do previsto, pois crescem no início da deterioração atingindo um valor máximo com 15 dias de armazenamento e depois decrescendo, pois a partir deste momento o peróxido começa a se autodegradar causando erros na leitura dos dados. Os valores sempre crescentes da TBA confirmam isto, pois apresentam crescimento durante todo o período de armazenamento.

As Figuras 5 e 6 mostram o comportamento dos valores de Îndice de peróxidos e TBA, durante o armazenamento. As testemunhas sem uso de vácuo apresentaram valores maiores para estes índices que os filés embalados a vácuo, o que pode ser facilmente justificado pelo fato da presença de oxigênio catalisar as reações oxidativas de óleos e gorduras [45].

Observou-se, então que mesmo que não sejam significantes, os valores da oxidação lipídica são influenciados pela temperatura, ou seja, o aumento de tempe- 
ratura provoca no produto um aumento na degradação lipídica do pescado e, principalmente pela presença ou não de oxigênio, o que vai influenciar nas propriedades sensoriais do produto e conseqüentemente na sua vidade-prateleira [4, 24].

A análise conjunta do produto aos 60 dias e da cinética do armazenamento dos filés nos mostra que o vácuo e a temperatura são significativos e eficazes no aumento da vida-útil dos filés de pescado até 60 dias. Cabe ressaltar que os parâmetros utilizados para análise do produto no caso do uso de embalagens a vácuo sempre apresentaram aos 60 dias, condições de consumo, pois os valores obtidos estão dentro dos padrões mínimos para consumo do pescado. Então, o tratamento mais eficaz no aumento da vida-útil do produto foi o uso de embalagens a vácuo com temperaturas de armazenamento de $2^{\circ} \mathrm{C}[1,13,21,26,32,33]$.

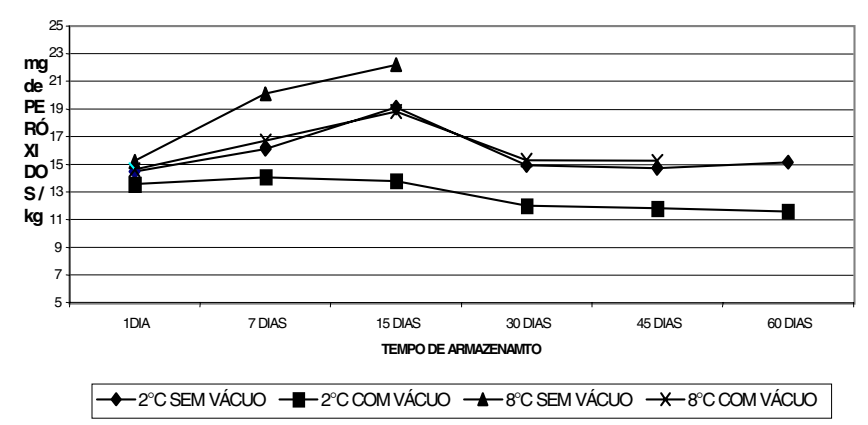

FIGURA 5. Cinética do comportamento do Índice de Peróxidos dos produtos.

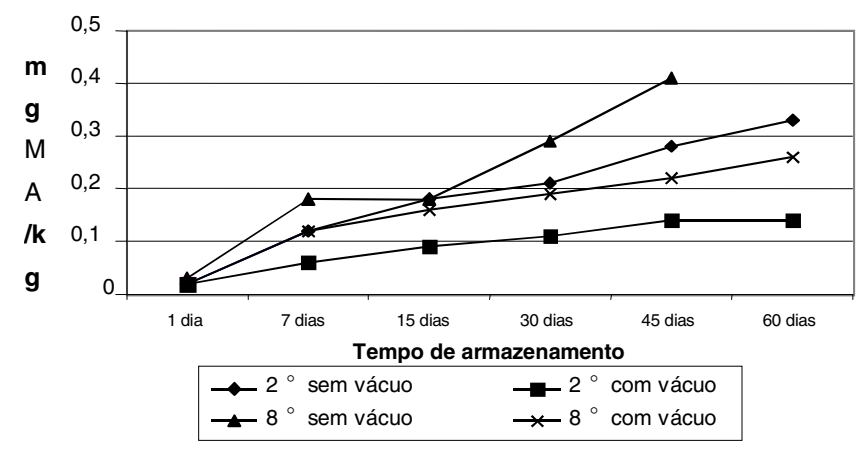

FIGURA 6. Cinética do comportamento do Índice de TBA dos produtos.

\section{4 - Teste de Clostridium sulfito redutor}

Para detectar riscos potenciais da presença da toxina ou de bactérias do gênero clostrídio, realizou-se então o teste preventivo para detecção de Clostridum botulinum, ou de clostrídio sulfito redutor nas amostras. Não foi detectada a presença destes microrganismos nos filés minimamente processados, o que mostra que o processamento mínimo provavelmente foi eficaz na remoção destes microrganismos e que não há risco de intoxicação pelas neurotoxinas que eles produzem [41].

Observa-se que embalagens com atmosfera modificada a vácuo, comportam-se semelhantemente a latas e que o pescado minimamente processado, devido ao próprio conceito deste tipo de processamento, não sofrem tratamento térmico, portanto não possibilitam, a eliminação do clostridium ou de sua toxina [23, 28]. Então o único meio de preservação do pescado à ação do clostridium ou da toxina botulínica é a refrigeração, pois o $C$. botulinum não prolifera ou apresenta qualquer tipo de atividade metabólica em temperaturas inferiores a $3,3^{\circ} \mathrm{C}$ [16, 31, 35]. Mas não existe nenhum estudo efetivo sob a ação do vácuo sobre metabolismo e crescimento do $C$. botulinum. Cabe ressaltar que a presença de bactérias do gênero Clostridium por si só, não representa um risco, pois elas só produzem a toxina se sentirem agredidas pelo meio ou entrarem em estresse, o que nesse caso não ocorre, pois o processamento mínimo não utiliza condições drásticas durante o processo tecnológico. [14, $25,36,42,43]$.

\section{4 - CONCLUSÕES}

As amostras embaladas a vácuo mostraram-se próprias para o consumo por um longo período, sendo a amostra armazenada a $8^{\circ} \mathrm{C}$ apresentou condições de consumo melhor por 45 dias, enquanto a armazenada a $2^{\circ} \mathrm{C}$ mostrou-se própria para consumo por até 60 dias sem problemas. Pôde-se observar uma perda de qualidade nas amostras que não foram embaladas a vácuo, tornando-se impróprias para o consumo a partir do quinto dia de armazenamento.

Também foi comprovado o significativo aumento na vida-útil do pescado refrigerado, chegando a se manter o produto em melhores condições de consumo por mais tempo que os métodos convencionais, o que tornou interessantes os resultados obtidos.

\section{5 - REFERÊNCIAS BIBLIOGRÁFICAS}

[1] ALCÂNTARA, M.R.S. Embalagens para pescados Enfoque em saúde pública. In: SIMPÓSIO E WORKSHOP: "TECNOLOGIA DE SALGA E DEFUMAÇÃO DE PESCADO”. Guarujá: ITAL, 1994.

[2] ALOR, F.A.R. Controle Microbiológico do Pescado e Derivados. In: SEMINÁRIO SOBRE CONTROLE DE QUALIDADE NA INDÚSTRIA DE PESCADO. ITAL - Instituto de Tecnologia de Alimentos. Santos. 1988.

[3] AOAC. Association of Official Analytical Chemist's. Official Methods of Analysis. 15a ed., Washington, 1997.

[4] ARAÚJO, J.M.A. Química de alimentos - Teoria e prática - Ed. UFV. 2a. Edição - 1999. 416 p.

[5] AYROZA, L.M.S. Manejo e tratamento pós-colheita de peixes de água doce destinados a salga e defumação. In: SIMPÓSIO E WORKSHOP: "TECNOLOGIA DE SALGA E DEFUMAÇÃO DE PESCADO”. Guarujá: ITAL, 1994.

[6] BERAgUET, N.J.; LINDO, M.M.K. Transformações bioquímicas Post Mortem em pescado. Boletim do ITAL, v.22. p. 169-192, 1985.

[7] BORGSTROM, G. Fish as Food. Vol.1-Academic Press. Nova York. 1961.

[8] BRODY, A.L. Controlled/ modified Atmosphere/Vacuum Packaging of Foods. Food Nutrition Press, Inc. USA, 1989.

[9] BRODY, A.L. Envasado de Alimentos en Atmósferas Con- 
troladas, Modificadas y Vacío. Editora Acribia, S. A. Zaragoza [España], 1996.

[10] BURGESS, G.H.O.; CUTTING, C.L.; LOVERN, J.A.; WATERMAN, J.J. El pescado y las industrias derivadas de la pesca. Editoral Acribia, Zaragoza, 392p, 1971.

[11] CHURCH, I.J.; PARSONS, A.L. Modified Atmosphere Packaging Technology: A Review. Journal of Science and Food Agricultural, v. 67, p. 143-152, 1995.

[12] CODEX STAN 165. Codex standard for quick frozen blocks of fish. 1998. In:http://www-seafood.ucdavis. edu/haccp/compendium/biological/cbotul.htm.

[13] CONTRERAS, E.S.G. Bioquímica de Pescados e Derivados. FUNEP, Jaboticabal. 1994.

[14] DOU. Diário Oficial da União. Padrões Microbiológicos em Alimentos. v. 124. 1998.

[15] FAO. Food and Agricultural Organization. Fisheries Index. Rome. 2001.

[16] FDA, Bacteriological Analytical Manual, $8^{\text {th }}$ ed. AOCAC International, Arlington, VA. 1995.

[17] FINNE, G. Modified- and controlled-atmosphere storage of muscle foods. Food Technology. v. 36, n. 2, p. 12833. 1982

[18] FRIMODT, C. Illustrated Multilingual Guide to the World's commercial coldwater fish. Turim, Itália. 1995. Turim, Itália. 1995.

[19] GARCIA, E.E.C.; PADULA, M.; SARANTÓPOULOS, C.I.G.L. Embalagens Plásticas: Propriedades de Barreira. Instituto de Tecnologia de Alimentos ITAL. CETEA. Campinas, SP. 1989.

[20] GIESE, J. How Food Technology Covered ModifiedAtmosphere Packaging Over years. Food Technology, v. 51, n. 6, 1997.

[21] GONCALVES, A.A. Estudo do processamento da anchova com aroma natural de fumaça. Rio Grande. 1998. Dissertação de Mestrado em Engenharia de Alimentos. FURG.

[22] HALL, G.M. Fish Processing Technology. VCH Publishers, New York. 1992.

[23] HUSS, H.H. El Pescado Fresco: Su Calidad y Cambios de Calidad. Colección FAO: Pesca, ONU / DANIDA Roma, 1988.

[24] HUSS, H.H.; JAKOBSEN, M.; LISTON, J. Quality Assurance in the Fish Industry proceedings of an International Conference, Copenhagen, Denmark, 26-30. 1991. ITAL, Centro de Tecnologia de Pescado. Seminário sobre salga e defumação de pescado. Campinas. 1995.

[25] LANARA, Métodos Analíticos Oficiais para controle de Produtos de Origem Animal e seus Ingredientes - Métodos Microbiológicos. Brasília - DF, 1981.

[26] LEISTNER, L.; RODEL, W. The stability of intermediate moister foods with respect to microorganisms. In: Intermediate Moisture Foods, R. Davies, G. G. Birch, K. J. Parker [eds], p.120-130. Applied Science, 1976.

[27] LEITÃO, M.F.F. Microbiologia e Deterioração do Pescado Fresco e Refrigerado de Origem Fluvial ou Marinha. Seminário sobre Controle de Qualidade na Indústria Pescado. ITAL. Santos, SP. 1988.

[28] LEMPEK, T.; LOPES, M.L.; PRENTICE, C.H. Efeito da embalagem a vácuo na qualidade do pescado consumido em Rio Grande. Anais do X Salão de Iniciação Científica da UFRGS. Universidade Federal do Rio Grande do Sul, Porto Alegre. Outubro, 1998.

[29] OGAWA, M.; KOIKE, J. Manual de Pesca. Associação dos Engenheiros de Pesca. Estado do Ceará. Fortaleza - Ceará, 1987.
[30] OGAWA, M.; MAIA, E. Manual de Pesca: C \& T do Pescado. Vol. 1. Ed. Varela, SP. 1999. 430 p.

[31] PASTORIZA, L.; SAMPEDRO, G.; HERRERA, J. J. Effects of mincing and frozen storage on functional properties of Ray muscle [Raja clavata]. J. Sci. Food Agric., v. 66, p. 35-44, 1994.

[32] PASTORIZA, L.; SAMPEDRO, G.; HERRERA, J.; CABO, M. Effect of Modified Atmosphere Packaging on ShelfLife of Iced Fresh Hake Slices. Journal Science Food Agricultural, v. 71, p. 541-547, 1996.

[33] RAIMUNDO, M.G.M. Formulações e Valor Nutricional de Produtos Elaborados a Base de Carne de Pescado Separada Mecanicamente [CPSM]. ITAL - Instituto de Tecnologia de Alimentos, Campinas, 1994.

[34] RANDELL, R.; AHVENAINEN, K.; LATVA-KALA, E.; HURME, T.; HYVONEN, L. Modified atmosphere packed marinated chicken breast and rainbow trout quality as affected by package leakage. J. Food Science. v. 60. n. 4. p. 667-672. 1995.

[35] REDDY, N.R.; ROMAN, M.G.; VILlANUEVA, M.; SOLOMON, H.M. Shelf life and Clostridium botulinum Toxin Development during Storage of Modified Atmosphere- Packaging Fresch Catfish Fillets. Journal of Food Science, v. 62, n. 4, 1997.

[36] ROLLE, R.S.; CHISM, G.W.III. Physiological consequences of minimally processed fruits and vegetables. J. Food Quality, v. 10, p. 157-177, 1987.

[37] SAINZ, R.L.; COSTA, A.C.; FONSECA, R. Frutas e hortaliças minimamente processadas, um novo mercado para a indústria da alimentação. ANAIS XII EPEAAF. Rio do Sul-SC. 1999.

[38] SÃO PAULO. NORMAS ANALÍTICAS DO INSTITUTO ADOLFO LUTZ. Métodos químicos e físicos para análise de alimentos, v. 1, 3o ed. São Paulo, 1985.

[39] SARANTOPOULOS, C.; SOLER, R.M.; OLIVEIRA, L.M.; PADULA, M. Novas Tecnologias de Acondicionamento de Alimentos. Cap. 5 e 6. Instituto de Tecnologia de Alimentos - ITAL. Centro de Tecnologia de Embalagens de Alimentos. Campinas, SP, 1988.

[40] SEAFOOD, Revista. Vacuum and atmosphere pakcaged fish and fishery.1999.http/seafood.ucdavis.edu/haccp/ compendium/chapt08.htm

[41] SEAFOOD, Revista. Clostridium botulinum: Compendium Ucdavis, Davis, 1997. http://www-seafood.ucdavis.edu/ haccp/compendium/biological/cbotul

[42] SILVA Jr., E.A. DA Manual de Controle Higiênico-Sanitário em Alimentos. Ed. Varela, São Paulo, 2a Edição, 1997.

[43] SIQUEIRA, R. Manual de Microbiologia de Alimentos. Ed. Embrapa, 1996.

[44] TORALlES, R.P.; SAINZ, R.L. Frutas e Hortaliças minimamente processadas. Módulo - Curso de Especialização em Ciência dos Alimentos. DCA / FCD / UFPel. 2001.

[45] WINDSOR, M.; BARLOW, S. Introduction to Fishery By-Products. Fishing Books, Farnham. 1984

[46] WILEY, R.C. Frutas y hortalizas minimamente procesadas y refrigeradas. Zaragoza, 1997, 362p.

\section{6 - AGRADECIMENTOS}

Os autores agradecem ao Frigorífico Castro S/A, à Direção Geral do Conjunto Agrotécnico Visconde da Graça da UFPel em Pelotas RS, e ao Dr. Mário Chimm Figueiredo do Laboratório de Aquicultura Continental da FURG, em Rio Grande, RS. 